\title{
A Propósito do Artigo: "Gastroenterite Aguda por Campylobacter spp: Casuística de uma Urgência Pediátrica"
}

\author{
Regarding the Article: "Acute Gastroenteritis by Campylobacter spp: a \\ Retrospective Study of a Paediatric Emergency Department"
}

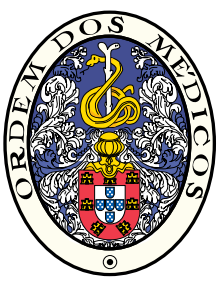

João M. VIDEIRA-AMARAL ${ }^{1,2}$

Acta Med Port 2014 Sep-Oct;27(5):535-536

Palavras-chave: Campylobacter; Infecções por Campylobacter; Criança; Gastroenterite; Serviço de Urgência Hospitalar; Portugal.

Keywords: Campylobacter; Campylobacter Infections; Child; Gastroenteritis; Hospital Emergency Service; Portugal.

Diversos estudos têm demonstrado que certas espécies (spp) da bactéria Campylobacter são agentes patogénicos na espécie humana e uma das principais causas de gastrenterite bacteriana, designadamente nos primeiros cinco anos de vida, com uma prevalência anual estimada de 500 milhões de casos nos países industrializados. Tais germes, com uma capacidade de invasão do epitélio intestinal, originando diarreia inflamatória com componente de adenite mesentérica, são isolados frequentemente das fezes de bovinos, porcinos, aves e animais domésticos. De referir igualmente a possibilidade de contaminação da água e de diversos alimentos como leite e carne crua mal cozinhada. Uma vez que o agente em causa, de acordo com estudos provenientes da medicina veterinária, tem sido isolado de fezes de animais domésticos como cães e gatos, aparentemente assintomáticos, poderá deduzir-se que as infecções pela bactéria referida têm implicações importantes em saúde pública. ${ }^{1}$

Os autores do artigo em epígrafe, ${ }^{2}$ tendo procedido a uma revisão casuística durante 30 meses, dão conta da sua experiência estudando retrospectivamente 6242 doentes com uma mediana de idade de 23 meses, os quais recorreram ao serviço de urgência de um hospital da grande Lisboa com o diagnóstico de gastrenterite aguda (GEA). Trata-se, segundo os autores, da maior casuística nacional sobre a problemática investigada, pelo que consideramos altamente louvável a publicação dos dados, demonstrando atitude de cidadania científica.

Salientando, no âmbito de tal instituição, a indicação rigorosa e bem estruturada dos critérios para execução de coprocultura como forma de investigação etiológica (a qual foi realizada em número de 216, desconhecendo o leitor se a relação número de coproculturas / número de doentes foi $1 / 1)$, os autores referiram a proporção de isolamento de germe da ordem de $45 \%$, comprovando-se como mais frequentes: Campylobacter responsável por metade dos resultados com isolamento positivo, e Salmonella correspondendo a $28 \%$ dos mesmos. Quanto aos isolamentos de Campylobacter a espécie mais frequentemente identificada foi $C$ jejuni (98\%) seguida de C coli $(2 \%)$. Comparando estes resultados com os de outros dois estudos nacionais sobre a mesma temática, aplicando metodologia idêntica, num deles predominou também Campylobacter e, em outro, predominou Salmonella.

De acordo com dados da literatura internacional, abstraindo a metodologia e os critérios para a realização de coproculturas, as percentagens de isolamento de Campylobacter spp em situações de GEA até aos cinco anos podem oscilar entre 4 e $46 \% .^{3}$

Para além doutro estudo citado pelos autores sobre investigação etiológica da GEA no nosso país, com objectivos e metodologia diversos, a nossa pesquisa bibliográfica identificou adicionalmente dois estudos portugueses sobre aspectos clínicos da infecção por Campylobacter spp, o que testemunha o interesse da comunidade científica pediátrica pelo tópico em análise..$^{4,5}$

As GEA por Campylobacter spp são classicamente consideradas situações benignas. Contudo, dado que a infecção pelo agente em causa pode assumir carácter sistémico e ou extra-intestinal, e que estão descritos na espécie humana casos de isolamento das fezes na ausência de sintomatologia, corroboramos a afirmação de muitos autores, com fundamento científico, segundo a qual a infecção pelo agente em causa, tem um espectro largo de manifestações oscilando entre estado assintomático e sépsis, o que depende de diversos factores, tais como: espécie infectante e poder invasivo da mucosa intestinal, assim como o estado imune do hospedeiro. ${ }^{1,3}$

Contabilizados os sinais e sintomas como formas de apresentação (deduzindo-se que, por vezes, associados) ressaltam, entre outros, no artigo em análise, os seguintes dados: diarreia aquosa - em $10 \%$ dos casos, diarreia com sangue - em $90 \%$, com sangue e muco - em $29 \%$, dor abdominal - em $29 \%$, vómitos - em $22 \%$, exantema - em $4 \%$, e febre - em $23 \%$. Somente dois casos requereram reidratação endovenosa. O internamento, em cinco doentes apenas, e durante menos de dois dias, poderá testemunhar a benignidade na maioria dos casos da amostra.

Por outro lado, os autores particularizam a evolução em $19 / 49$ casos $(38,7 \%)$ sem especificarem se os quadros

1. Chefe de Serviço/ Director ex-officio. Clínica Universitária de Pediatria. Hospital de Dona Estefânia. Lisboa. Portugal.

2. Professor Catedrático Jubilado. Faculdade de Ciências Médicas. Universidade NOVA de Lisboa. Lisboa. Portugal.

Recebido: 24 de Outubro de 2014 - Aceite: 24 de Outubro de 2014 | Copyright @ Ordem dos Médicos 2014 
descritos correspondem, sob o ponto de vista nosológico, a formas evolutivas da infecção a ser investigada, ou a complicações: um caso de sépsis em criança com 36 dias de vida, e 18 casos de diarreia prolongada com sangue, obrigando a internamento. Ora, considerando estes dados objectivos (38,7\%), mesmo admitindo que o desfecho na totalidade foi favorável, a afirmação nas linhas finais do artigo de 'reduzido número de complicações' poderá ser considerada questionável.

Sobre o caso de sépsis, parece-nos oportuno referir, por associação de ideias, que a bacteriémia por Campylobacter spp é pouco frequente ( 1/ 1000 doentes), ocorrendo sobretudo em crianças malnutridas e ou com défice imunitário: podem estar implicadas espécies mais frequentes como $C$ jejuni e $C$ coli, ou mais raras, como $C$ upsalensis ou $C$ concisus. Estão também descritas infecções perinatais associadas mais frequentemente a $C$ fetus podendo originar parto pré-termo, aborto, morte fetal, e sepsis com ou sem meningite..$^{1,3,6}$

E a propósito da infecção por Campylobacter spp, cabe referir que na literatura científica têm sido consideradas complicações os quadros clínicos de patogénese imunorreactiva tais como síndroma de Guillan-Barré, síndroma hemolítica urémica, artrite, eritema nodoso, etc. ${ }^{1,3,5,6}$

Os autores, reconhecendo ser importante identificar

\section{REFERÊNCIAS}

1 Granado-Vilar D, Cunill-De-Sautu B, Granados A. Acute gastroenteritis. Pediatr Rev. 2012;33:487-95.

2 Soares AT, Couto C, Romão P, Melo IS, Braga M, Diogo J, et al. Gastroenterite aguda por campylobacter spp: casuística de uma urgência pediátrica. Acta Med Port. 2014;27:556-60.

3 Long S. Principles and practice of pediatric infectious diseases. London: Churchill-Livingstone/Elsevier; 2012.

4 Valente I, Aguiar AL, Afonso A, Coelho E, Costa M, Aroso S, et al. Gas- fontes de infecção, terminam o artigo com uma reflexão autocrítica traduzindo uma limitação do estudo, (retrospectivo). Tal como muitos outros, entendemos que havendo limitações, haverá igualmente oportunidades para mudanças e avanços. Reconhecendo o mérito do estudo, entendemos que a idoneidade dos autores constitui garante para prosseguir a investigação e, por isso, para a ampliação do conhecimento sobre a história natural da infecção por Campylobacter spp no nosso País, relativamente a zonas que os estudos nacionais até então não abrangeram. Existe um manancial de áreas que requerem aprofundamento em estudos prospectivos multi-institucionais e multi-disciplinares, designadamente com a colaboração dos investigadores nas áreas da biologia e da medicina veterinária. Efectivamente, ainda faltam respostas a muitas perguntas.

Em suma, os problemas da biologia do germe, da co-infecção (há autores que contestam a patogenicidade da bactéria, que dependerá da condição de 'só ou acompanhado'), das fontes de infecção - que poderão variar de região para região, dos portadores assintomáticos, e dos reservatórios de germes, entre outros, constituem, no nosso entendimento, linhas de investigação exequíveis e pertinentes, seguramente com impacte na melhoria das estratégias de prevenção e tratamento.

troenterite aguda na criança, estudo prospectivo multicêntrico. Nascer Crescer. 2006;15:159-60.

5 Rodrigues F, Costa Alves M, Alves AF, Lemos L. Etiologia das gastroenterites agudas em unidade de internamento de curta duração: estudo prospectivo de 12 meses. Acta Pediatr Port. 2007;38:13-7.

6 Wiegering V, Kaiser J, Tappe D, Weissbrich B, Morbach H, Girschick HJ. Gastroenteritis in childhood: a retrospective study of 650 hospitalized pediatric patients. Int J Infect Dis. 2011;15:401-7. 


\section{A Propósito do Artigo: "Gastroenterite Aguda por Campylobacter spp: Casuística de uma Urgência Pediátrica"}

Acta Med Port 2014:27:535-536

Publicado pela Acta Médica Portuguesa, a Revista Científica da Ordem dos Médicos

Av. Almirante Gago Coutinho, 151

1749-084 Lisboa, Portugal.

Tel: +351218428215

E-mail: submissao@actamedicaportuguesa.com

www.actamedicaportuguesa.com

ISSN:0870-399X | e-ISSN: 1646-0758

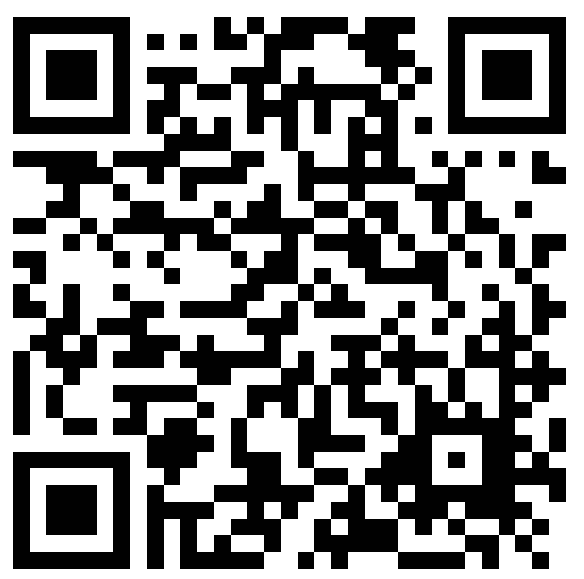

